\title{
Diálogos sobre educación democrática: mirada intercultural de la formación de ciudadanos latinoamericanos
}

\author{
Dialogues on democratic education: Intercultural view of the \\ development of Latin American citizens
}

\author{
Nelson M. Manzanero* y Miguel Y. Ramírez ${ }^{* *}$
}

\section{RESUMEN}

Algunos miembros de la sociedad pregonan la carestía del establecimiento del diálogo de culturas, cuya esencia integre tejidos de perspectivas y categorías sobre relaciones, lo igual y lo diferente, la tradición, la innovación, entre otras categorías. Es bajo este supuesto que surge la interculturalidad como una acción consciente y concertada por parte de los implicados que promueva una actitud de diálogo inter/intrapersonal, principios esenciales de la educación democrática y la formación de ciudadanos. El presente artículo tiene como propósito fundamental el develar la construcción teórica de la educación democrática en escenarios interculturales en contextos latinoamericanos, a la luz de sustentos teóricos que sirven de base referencial, de autores como: Apple y Beane (2005), Dewey (2004), Alarcón (2012) Fornet Betancourt (2009), Salas Astraín (2003), Ramírez (2005), entre otros, por medio de una metodología revisión y análisis documental hermenéutica. La conversación entre los autores al interior del artículo permitió responder cuestionamientos relacionados con lo que se espera del sujeto en formación en los contextos democráticos actuales en Latinoamérica y cómo tiene lugar la gestación de ciudadanos a partir de procesos interculturales y fundamentando dicha instrucción en los principios propios de la democracia. Por último y como conclusiones puntuales, se destacan los cimientos de una educación democrática que surgen como simbiosis ineludible entre los parámetros

\footnotetext{
"Licenciado en Educación Básica Integral egresado de la Universidad del Zulia, Magíster Scientiarum en Ciencias de la Educación - Gerencia Educativa de la Universidad Dr. Rafael Belloso Chacín, ambas instituciones en la ciudad de Maracaibo - Venezuela. Doctorante del Programa doctoral de la Universidad Internacional Iberoamericana. Autor de publicaciones tanto en español como en el idioma inglés (Desarrollo Humano para adolescentes I y II / Human Developmentforteenagers I and II) de la Editorial Trillas en México. Monterrey, México. Correo electrónico: nmanzanero@hotmail.com; nelson.manzanero@udem.edu

${ }^{* *}$ Profesor-Investigador en la Universidad Internacional Iberoamericana, Doctor en Educación. Adicionalmente es Maestro en Dirección Estratégica, Master in Business Administration y Licenciado en Informática. Ha colaborado en la administración pública federal y local, y en empresas privadas. San Francisco de Campeche, México. Correo Electrónico: miguel.ramirez@unini.edu.mx; miguelyramirez@hotmail.com
}

101 
Diálogos sobre educación democrática: mirada intercultural de la formación de ciudadanos latinoamericanos

formativos de una sociedad y el poder que la rige, aunada a la premisa que proyecta a la escuela como una institución de formación y espacio óptimo para la instrucción de tales ciudadanos con identidades particulares, que permitan la convivencia desde la diversidad, y la construcción de valores, entendiendo que los jóvenes son sujetos activos responsables de su proceso, más que objetos vacíos prestos para el llenado automático de valores universales impuestos, ajenos a ellos.

Palabras clave: Educación Democrática, Interculturalidad, Formación de Ciudadanos, Cultura, Pedagogía Intercultural.

RECIBIDO: Octubre 2017
ACEPTADO: Noviembre 2017

\begin{abstract}
Some members of the society make public the lack of the establishment of dialogue of cultures, that its nature integrates several perspectives and categories about relations, the usual and unusual, the tradition, the innovation, among others. It's under this assumption that the interculturality as a conscious and concerted action by those involved would promote an attitude of interpersonal dialogue, essential principles of the democratic education and the citizen formation. The main purpose of this article is to unveil the theoretical construction of the democratic education in intercultural scenarios, basing on the theoretic perspectives of the following authors: Apple $y$ Beane (2005), Dewey (2004), Alarcón (2012) Fornet Betancourt (2009), Salas Astraín (2003), Ramírez (2005), among others, through a review methodology and hermeneutic documentary analysis. The conversation between the authors allowed to answer some questionings related to the expectations of the ones in formation in the actual democratic contexts in Latin America and How the development of citizens take place from intercultural processes and grounding this instruction on the democracy's principles. Finally and as a conclusion, the foundations of a democratic education are articulated as an inevitable symbiosis between the formative parameters of a society and the power that administrates it, in addition to the premise that visualizes the school as a formation institute and ideal instruction space of those citizens with particular identities that would allow the gathering from the diversity and the values construction, understanding that the youths are responsible and active people of their own processes, more than empty objects for the automatic filling of universal and imposed values, completely alien to them.
\end{abstract}

Keywords: Democratic Education, Interculturality, Formation of Citizens, Culture, Intercultural pedagogy. 
Nelson M. Manzaneroy Miguel Y. Ramírez

Telos Vol. 20, No. 1 (2018). 101-128

Introducción

El arte de educar para la formación de una comunidad cuyos integrantes participen de forma activa en el quehacer social, demanda pasar de un pensamiento de democracia formalista, propia del contexto político, a una concepción diferente de colectividad democrática de aprendizaje, enmarcada en referentes puntuales a una institución que se precisa como educativa/formativa.

Una educación democrática, en el sentido más global implica una formación para la democracia y en democracia, lo cual se conforma a su vez en la intensión final y una orientación puntual en largo camino llamado educación. Según Bolívar (2016) las estructuras educativas deben capacitar a los ciudadanos de las comunidades del futuro "para poder participar activamente en la esfera pública sin riesgo de exclusión, lo que supone asegurar que toda la población adquiera aquellas virtudes, conocimientos y habilidades necesarios para la participación política y la inserción social" (p. 69).

Los ciudadanos de las sociedades actuales, regidas por sistemas democráticos se hacen, no nacen, pues la democracia como estructura de participación cuyos cimientos axiológicos son referentes de valores universales, se aprende, se forma, se modela; en consecuencia, se debe enseñar, y ejercer en el tiempo. La educación se constituye, entonces, en el medio adecuado por excelencia a través del cual se pueden transferir las moralidades ciudadanas que viabilizan la convivencia en cualquier democracia. Si la intención global se centra en la preservación de la democracia de forma tangible y perpetua, el reto inicial es sin duda, el impulso de una educación para sujetos activos, que se conformen como ciudadanos potenciales del presente y más aún del futuro.

La democracia, propiamente dicha, debe ser vislumbrada como una manera de interrelación entre los ciudadanos y una vida comunitaria de los diferentes estratos sociales, cuya implantación debe coincidir con la formación de jóvenes en interacción con unas determinadas condiciones sociales y políticas en sus vidas denotando, a su 
Diálogos sobre educación democrática: mirada intercultural de la formación de ciudadanos latinoamericanos

vez, rasgos conceptuales evidentes de interculturalidad, en donde no solo el proceso de comunicación e interacción entre personas y grupos diversos es vital, sino también necesario para la construcción conjunta de cultura y una sociedad democrática.

En tal dinámica de formación de ciudadanos, surgen en consecuencia las nociones elementales de una cultura, entendida por Salas Astraín (2003) como un:

"Conjunto de representaciones que los individuos tienen del mundo y de sí mismos, de los valores desde los que son apreciadas las acciones, de las modalidades materiales y formales a partir de las cuales las representaciones y valores encuentran sus proyecciones concretas, $y$, por último, de las mediaciones técnicas y sociales" (p. 74).

En consecuencia, De Vallescar (2013) plantea que una aproximación al diálogo entre culturas, entendido como vestigios de interculturalidad, podría integrar un cruce de perspectivas y categorías, a saber: las relaciones, lo igual y lo diferente, la tradición, la innovación, entre otras categorías. Es bajo este marco que la autora llega a afirmar que la interculturalidad es una acción consciente y concertada por parte de los implicados, no una mera recepción de elementos socioculturales sostiene el hecho de no poder "vivir la interculturalidad sin una actitud de diálogo inter/intrapersonal" (p. 59), principios esenciales de la educación democrática y la formación de ciudadanos.

Desde esta perspectiva la escuela como tal, debe jugar a favor de la instrucción de tales ciudadanos con identidades particulares, que permitan la convivencia desde la diversidad, y la construcción de valores, entendiendo que los jóvenes son sujetos activos responsables de su proceso, más que objetos vacíos prestos para el llenado automático de valores universales impuestos, ajenos a ellos.

\section{De las conversaciones sobre la cultura: Nociones y actores}

Atendiendo a la premisa anteriormente citada sobre la cultura, es menester comprender también que tales representaciones involucran quehaceres históricos y/o 


\section{Nelson M. Manzaneroy Miguel Y. Ramírez.}

Telos Vol. 20, No. 1 (2018). 101-128

procesos sociales que tienen un significado en el andar social del mundo de vida de cada sujeto viviente, en este punto se hace necesario acordar con los planteamientos de García Canclini (2006).

Froufe Quintas (2015) afirma que el término cultura, tras experimentar un deslizamiento etnocéntrico del ámbito agrícola, donde era utilizado para darle atención y cuidado a las semillas para fructificar, incluye las costumbres, hábitos, creencias, y artes de cualquier pueblo. Desde este punto de vista, la cultura puede entenderse como un proceso de formación del hombre, la suma de todas las ideas, donde el entendimiento humano es el elemento central, más allá de los factores ambientales, económicos, entre otros. Lo importante, que puede deducirse de esta definición, es que la cultura no se centra en los objetos o fenómenos materiales, sino en la forma como ellos se estructuran y organizan en la mente del hombre. La cultura como tal, da consistencia a las diferentes características de los pueblos, ya que permite la expresión de su forma de ser y de existir como sujeto colectivo que son.

De lo anterior puede desprenderse que existen otros elementos que entran en juego, a la hora de definir a la cultura como lo son la contextualidad e historicidad, que son a su vez considerados como indispensables para explicar dicho término, puesto que ellos develan el arraigo que puede tener cada cultura en los seres humanos. En otras palabras, y haciendo uso de las ideas planteadas por los autores mencionados: tanto la contextualidad como la historicidad demuestran que los seres humanos, en grupos sociales, se organizan en función de los fines y valores que quieren realizar, de ahí que los elementos comentados diferencien a un grupo de otro, haciéndolo único e irrepetible. Aproximarse a la cultura tomando en cuenta lo planteado, trae, a su vez, significaciones reflejadas en prácticas manifiestas que abarcan la dinámica existente que se constituye entre la comprensión propia y aquella que surge de la intersubjetividad envuelta en el diálogo cultural continuo de seres en correlación.

Es así como, autores como Salas Astraín (2003),sostienen que, para la comprensión de un sujeto latinoamericano, es imprescindible, el acercamiento a su 
Diálogos sobre educación democrática: mirada intercultural de la formación de ciudadanos latinoamericanos

cultura, vista desde sus tradiciones, costumbres, y pensamientos, es decir, desde la lógica inmersa en su constitución como ser humano perteneciente a esa cultura. Se podría agregar lo señalado por Strauss (citado en Della Ventura, 2016) cuando señala que lo cultural es lo universal, este autor naturaliza su concepto, buscando una suerte de proceso intercultural que desde el intercambio podría neutralizar el carácter historicista de la cultura.

Las culturas, concebidas desde esta perspectiva, van un paso más allá de lo que abarcan sus tradiciones, a pesar de que éstas les otorga rasgos distintivos, no abarcan explicaciones únicas sobre su evolución y hasta su progreso. Elementos que la conforman, tales como la memoria y la experiencia, invitan a la comprensión de tradiciones que luchan entre ellas para definir lo propio, convirtiéndose en un conflicto por el poder, no solo práctico sino hermenéutico, pues muestra la lucha por la hegemonía de la interpretación de significados y sentidos. Sin embargo, es importante señalar que dentro de una misma cultura tales tradiciones pueden estar marcadas por la mirada de aquel que las pretende, bien sea para reafirmarse o para modificarse, en términos de Fornet-Betancourt, para innovarse.

Es por lo anterior que se puede afirmar que ser miembro activo de una cultura y reconocerse como sujeto dentro de ella, va de la mano con el saberse parte de un mundo indeterminado en su totalidad, lo cual dicho, en otras palabras, implica el análisis dela cultura desde las particularidades que la caracterizan y hasta la definen. Si esto es así, como plantean autores como Fornet-Betancourt (2009): ¿Cómo se comete el error de aproximarse a culturas desde el uso monocéntrico occidental? Más aún: ¿Cómo puede concebirse en algunos espacios como la voz que silencia al resto, imponiendo el pensamiento inherente a un estilo de vida ajeno?

Este autor y otros sostienen que, a través de los procesos de globalización, la pretendida hegemonía de Occidente, usualmente ajeno a las diferencias culturales latinoamericanas, específicamente, ha hecho que los sujetos de la cultura local se preocupen por estas cuestiones, buscando respuestas válidas a las interrogantes 


\section{Nelson M. Manzaneroy Miguel Y. Ramírez.}

Telos Vol. 20, No. 1 (2018). 101-128

planteadas, haciendo énfasis en el reconocimiento de las diferencias y el respeto al otro. De ahí que filósofos como los mencionados anteriormente, establezcan como escenario posible para el reconocimiento y encuentro de culturas, la interculturalidad.

Se hace evidente, hasta este punto que las culturas tanto en su historia como contexto, no suponen, ni establecen homogeneidad social; las interpretaciones que se hacen sobre ellas, están marcadas, entre otras, por la influencia de culturas ajenas que se han vendido como propias, así como por los procesos de opresión-liberación, usualmente encontrados entre las letras de algunos filósofos latinoamericanos. Las diferencias que pueden observarse entre las clases dominantes-marginalizadas por diversas causas, hacen visibles las tensiones que estos procesos han traído consigo a este continente. Dichas situaciones han invitado al estudio de la cultura con un marco referencial auténtico, que no deja de ser propio y que las dota de características únicas dispuestas para el encuentro entre sus historias, contextos, formas, significaciones y sentidos.

\section{De la Interculturalidad como encuentro de culturas hacia la pedagogía intercultural}

Autores como Fornet-Betancourt, Salas Astraín, Roig, De Vallescar, Manzanero-Márquez, plantean desde sus especialidades que el camino posible para el alcance del reconocimiento - respeto - encuentro de culturas, es efectivamente la interculturalidad, siendo el espacio propicio para ello, el diálogo intercultural. Este lo conciben, parafraseando las palabras de uno de ellos como aquel donde las historias son transmitidas, por medio de narraciones primarias, mostrando cómo han llegado a ser, lo que son actualmente, (Fornet-Betancourt, 2009). El propósito central de los diálogos de esta naturaleza, es el "ennoblecimiento del ser humano", el instrumento para la consecución de la diversidad en el mundo histórico actual (ManzaneroMárquez, 2014). 
Diálogos sobre educación democrática: mirada intercultural de la formación de ciudadanos latinoamericanos

Esta autora afirma que, si bien el diálogo de las culturas supone lo anterior, para que el encuentro sensible con el otro tenga lugar, tendrían que coincidir varios elementos como la presencia de subjetividades emergentes en una misma cultura, la construcción de nuevos contextos y la pluralidad de saberes sobre sus identidades (Manzanero-Márquez, 2014). Visto de este modo, la interculturalidad, puede concebirse fuera de los linderos teóricos culturales, como opción diferente a las impuestas por Occidente mediante el proceso de globalización, acorde a lo que plantea Fornet-Betancourt (2000).

Tomando como premisa lo anteriormente expuesto, se puede afirmar que el análisis exhaustivo de las culturas, debe partir de la premisa que éstas no pueden ser tratadas como bloques unificados de sentidos, donde los significados giren en torno a una misma mirada o misma razón de ser, pues es necesario acercarse a ellas desde la apertura tácita que implica el estudio de mezclas y diferencias propias del sujeto viviente que las vive y las practica. En otras palabras, la historia político social y cultural de Latinoamérica, dicta a cualquiera que pretenda acercarse a ella, la búsqueda de condiciones para interpretar las líneas continuas que explican el devenir de los pueblos inmersos en ellas; la recomendación básica que lleva de las manos estas intenciones, son las propuestas por Manzanero-Márquez (2014), cuando propone que:

"La diversidad implícita en la construcción de valores y tradiciones que los sujetos movilizan desde sus particularidades, llevan a la conclusión que lo plural en una característica indispensable en el diseño de tan complejo proyecto nombrado filosofía latinoamericana de apellido intercultural” (p. 49).

De ser cierto lo planteado, autores como Fornet-Betancourt (2009) se hacen la pregunta si el latinoamericano sabe lo que debería saber o si, por el contrario, no sabe lo que debería saber. Esta premisa hace referencia a las culturas del saber, que entran en juego igualmente en los procesos interculturales, las cuales son consideradas por algunos autores como asimétricos; de ahí que el autor sostenga que para que el 


\section{Nelson M. Manzaneroy Miguel Y. Ramírez.}

Telos Vol. 20, No. 1 (2018). 101-128

latinoamericano sepa lo que se supone debe saber, el encuentro con otra cultura debe hacerse en condiciones de igualdad y simetría.

Es ampliamente conocido y comentado, por los diferentes autores que se han discutido a lo largo del artículo, que América Latina se encuentra bajo el marco referencial de una cultura dominante ajena, la cual se deja ver entre las aulas y programas de las casas de estudio más importantes del Continente; ante esa realidad, se podría concluir, que el latinoamericano como tal, no sabe lo que debería saber, ya que lo existente en América Latina no permite el encuentro simétrico entre culturas, específicamente las del saber, ya que éstas se deben obtener a través de la interacción simétrica con ellas, como lo plantea Fornet-Betancourt (2009).

A propósito de lo comentado, autores como Froufe Quintas (2015) afirman, con respecto a esta temática, que se perciben resistencias profundas dentro de los estos contextos sociales, que bien podrían dificultar ampliamente la posible adaptación y hasta renovación educativa del perfil cultural de cada nación o de cada pueblo. Acota de igual manera, que la función pedagógica de la escuela dentro de este proyecto de apertura, al entendimiento y comprensión de otras culturas, ha sido esencialmente reproductora, en cuanto a la internalización de esquemas o conquistas intelectuales ajenas a Latinoamérica como tal. Esta expansión agresiva del saber occidental representa una dificultad para el encuentro de culturas a nivel amplio, convirtiéndose en un peligro real para la diversidad epistemológica del mundo, por tanto, el discutir sobre estos asuntos devela la intención de reivindicar dicha pluralidad, llevando con ello a la protección y el fomento de la diversidad cognitiva, dominada por demás.

Esta situación, obliga a construir nuevos enfoques en diferentes ámbitos como el pedagógico, que invite a la eliminación de barreras tales como las físicas, ideológicas, axiológicas, culturales, entre otras, a través del diseño de nuevos currículos dentro de la formación de un perfil adecuado de profesores y la enseñanza de seres humanos en tolerancia, respeto y reconocimiento del otro diferente y perteneciente a otra cultura. El cambio visto desde este punto de vista, debe estar 
Diálogos sobre educación democrática: mirada intercultural de la formación de ciudadanos latinoamericanos

centrado en aspectos actitudinales, cognitivos, entre otros que tengan como propósito evitar que principios legales existentes o instruccionales oculten posibles prácticas discriminatorias.

Lo complejo en la realización de esta propuesta de diálogo simétrico, son los elementos que trae consigo para su concreción, pues son las formaciones sociales, la educación, entre otras, las que entran en juego sin invitación; con las reglas definidas, a saber, el respeto y el reconocimiento del otro como diferente, con los mismos derechos y deberes que cualquiera, mucho más aún sin el encasillamiento en categorías o jerarquías familiares. A esto podría unirse que asumir el saber científico dominante, no debe considerarse como regla para el desarrollo cognitivo universal, tal como se comentaba en líneas anteriores.

Visto de este modo, puede considerarse que la premisa manejada por Manzanero-Márquez (2014), cuando afirma que la consecuencia lógica es la pluralidad epistemológica predicada y necesaria cuando se habla de interculturalidad, quede relegada a un segundo plano, perdiendo así, sentido a nivel general. En la era globalizada que se vive actualmente por estos lares, tiene una mayor importancia el acceso que se tiene a la información, cuán rápido se accede o cuánta se obtiene, entendiendo el término información como conocimiento, más que la calidad o el manejo que se hace de él.

Para esta autora, este acceso al saber de igual manera, trae consigo otras preguntas: “¿Se necesita participar en esta configuración del saber? y si es así ¿Para qué se necesita? ¿Qué tipo de saber y de ser humano se maneja en esta concepción?” (p. 52). Las respuestas que proponen los autores se presentan de la mano de FornetBetancourt (2009), cuando sostiene que es importante repensar críticamente la cuestión del acceso al saber y ver qué consecuencias conlleva para la reivindicación de la pluralidad epistemológica. En otras palabras, el saber que se promueve desde Occidente es un saber instrumentalizado, ése que capacita al ser humano para la realización eficaz de tareas demandantes para el perfecto encaje en el mundo actual. 


\section{Nelson M. Manzaneroy Miguel Y. Ramírez.}

Telos Vol. 20, No. 1 (2018). 101-128

Aunque bien podría decirse que el argumento detrás de estos planteamientos es la insoportable verdad de no estar a la altura de la información que se maneja en el llamado primer mundo, o el acceso que se tiene a ella. Sin embargo, nada de lo anterior es cierto, más bien, la intención de las pretensiones de los que escriben sobre estas temáticas están dirigidas a no dejas atrás las particularidades de la cultura propias, tratando de vivir al ritmo de los avances contextuales. En palabras de FornetBetancourt (2009): “el ritmo de seres humanos vivientes es un ritmo lento, demasiado lento para un saber que tiene que acelerar tanto su ritmo innovador...” (p.15).

Si se toma lo expuesto como cierto, el ser humano en Latinoamérica corre el riesgo de "quedarse atrás" o estar fuera, como una posición ante la vida que le ha sido vendida para hacer viable su status de permanencia o inercia en el tiempo. Los ritmos que el mundo globalizado ofrece son distintos a los que el ser humano en América Latina representa, esto en cuanto a la construcción del conocimiento. Con esto no se quiere justificar la lentitud falsamente creída en algunas esferas del mundo de vida del ser latinoamericano; los ritmos temporales de sus propias dinámicas en este Continente son diferentes. Por lo tanto, es desde la diversidad cultural en sus diversos tiempos que los diálogos simétricos mencionados en líneas anteriores, construyen realidades análogas y compartidas.

Los saberes instrumentales, no buscan las transformaciones desde las singularidades de los sujetos que viven cada cultura, sino, por el contrario, son admitidos para la cultura hegemónica, como el único camino visible y posible para enfrentar los problemas y evadir los conflictos propios que se van presentando. Desde esta perspectiva los saberes populares, son olvidados y sustituidos por los no propios, esto demarca de manera indiscutibles los escenarios en América Latina. De ahí que autores como Fornet-Betancourt, Roig, Salas Astraín comenten que el punto de partida del que pretenda acercarse a los estudios de estas realidades, es concebir la pluralidad epistemológica como protagonista (Manzanero-Márquez, 2014). 
Diálogos sobre educación democrática: mirada intercultural de la formación de ciudadanos latinoamericanos

Partiendo de lo anterior, se sigue que la revisión de asimetrías impuestas para restringir o controlar espacios de encuentros y condiciones en el diálogo de culturas, deberá favorecer la aparición de espacios reales de coexistencia dialógica que den lugar a las verdaderas condiciones comunicativas que trae consigo el encuentro de subjetividades inmersas en el juego intercultural actual. En palabras de Salas Astraín (2003), es la preocupación real de no quedarse con lo impuesto y ligeramente familiar, sino de ir más allá, de las teorías e ideas, asumiendo que detrás de ellas están las epistemes de aquellos que viven y sienten la cultura. El acercamiento se hace desde esta perspectiva crítica de la naturaleza cultural, social y hasta política, en América Latina.

Es indiscutible que la discusión que se pretende gira en torno a los saberes que conversan con los valores y las costumbres del pueblo latinoamericano, sin dejar a un lado los conflictos éticos latentes en el encuentro propuesto de las culturas. Al respecto, dicho autor también comenta que las condiciones básicas para la reconstrucción de un diálogo en Latinoamérica, pasan por una ética intercultural, de índole filosófica, que apuesta por ella, asegurando el vínculo de reciprocidad entre los nuevos modos de vida.

Lo escrito va de la mano con la propuesta que hacen los autores que promueven una pedagogía de la interculturalidad que invita al cambio paulatino de las iniciativas pedagógicas, así como su inserción el experiencias socioculturales originarias, a los procesos de intervención de la mano de la escuela como institución formadora/educadora. Por lo tanto, se hace evidente el cambio o la reformulación que deja ver lo propuesto en los proyectos educativos que contemplan el acceso a las diferentes culturas, y cómo éstas sean capaces de convivir y reconocerse mutuamente en contextos socio históricos culturales compartidos. En otras palabras, propiciar la construcción de una pedagogía intercultural significa que cada uno de los inmersos en alguna cultura se apropie de la identidad formativa y hasta ecológica, que sean capaces de compartir con los otros, bienes, atributos y voluntades que han logrado 


\section{Nelson M. Manzaneroy Miguel Y. Ramírez.}

Telos Vol. 20, No. 1 (2018). 101-128

desarrollar d acuerdo a sus prácticas culturales originarias, esto con el fin de afianzar modos de convivencia pertinentes a na cultura de paz, mediada por el diálogo intercultural entre los seres humanos.

Los planteamientos hechos, bien podrían ser considerados como una utopía contemporánea, difusa en sus linderos invisibles para cualquiera que se acerque a ellos para una revisión exhaustiva de los mismos; sin embargo, las intenciones caminan en una dirección opuesta, pues el anhelo tácito detrás del escrito es mostrar los distintos escenarios del mundo de vida que el sujeto latinoamericano ha asumido como suyo para pensarse y sentirse. Esto involucra un estar siendo perseen los procesos históricos-político-sociales-culturales vividos, que los llevaron a configurar las representaciones sociales de la manera en que se presentan ante el mundo (Manzanero-Márquez, 2014).Es así como, al hablar de diálogo intercultural, interesa destacar que los encuentros entre interlocutores permiten matizan esa esfera del encuentro con el otro que da génesis a un nosotros que construyen a partir de los saberes y realidades donde los actores generan sus propios contextos de interacción.

\section{Acerca de la formación de ciudadanos democráticos}

Tal y como se menciona en los apartados anteriores, las sociedades de hoy construyen sus significados a partir de las constantes interacciones que surgen del encuentro de individuos que las componen y las definen. El diálogo respecto a intereses y necesidades de realidades particulares, emerge como producto de prácticas características que engloban la esencia de lo diverso y conforman conocimientos comunes, sistemas normalizados por medio de elementos propios que se integran y reproducen ciertas estructurasque responden a los principios culturales que dictaminan las conductas aceptadas o bien señaladas, dentro un grupo social similar o heterogéneo entre sí.

Es decir que las dinámicas humanas en espacios de convivencia de sujetos culturalmente organizados, obedecen a códigos socialmente aceptados y que 
Diálogos sobre educación democrática: mirada intercultural de la formación de ciudadanos latinoamericanos

previamente constituidos son parámetros legales que rigen el estilo de vida de los que la conforman. Es así como cada sociedad se comporta de acuerdo al ideal que profesa, $\mathrm{y}$, por ende, debe admitir, formar y preparar individuos que, actuando bajo esquemas de comportamientos totalmente opuestos en ocasiones, se confronten y entrelacen en todo momento con el interés de producir una trama social que les brinde un bien común compatible con la diversidad de la sociedad.

Es imposible hacer referencia a la sociedad actual, sin aludir a la presencia de múltiples grupos humanos cuya característica de mayor peso es el pluralismo democrático que en términos de ideales y sistema de valores se pronuncia por un régimen de gobierno de mayor participación directa por parte de la ciudadanía en los asuntos del Estado de derecho. Es por esto que la tendencia actual de las democracias, donde la ciudadana es representada por el sujeto de la acción política, es lograr una trama social que refleje la heterogeneidad de sus espacios institucionales constituyentes. Modelos de representación política que en su mayoría son definibles como democráticos porque necesitan en todo momento establecer mecanismos de formación para generar la dialogicidad que debe alimentar el consenso y la negociación de los intereses y necesidades, con el objetivo de imprimir una conducta plenamente participativa en sus procesos de legitimación y legalidad haciendo de sus diferencias una confluencia de diversidad y virtudes comunes.

Muy probablemente uno de los conceptos más controversiales y vulnerables a posturas diversas de opinión, es el de la democracia considerada como ente formal de la política, pues su interpretación está en referencia a los contextos particulares en los que se gestan sus valores y prácticas normativas, vale decir, el orden jurídico-político que le sirve de sustento. Hoy día, el rol de la democracia está muy en consonancia con los episodios que acontecen en las realidades históricas globales o locales, y un sin fin de formas ideológicas colectivas de los propias clases hegemónicas o insurgentes que hacen vida en el espacio público. 


\section{Nelson M. Manzaneroy Miguel Y. Ramírez.}

Telos Vol. 20, No. 1 (2018). 101-128

Las experiencias políticas en Latinoamérica demuestran que los modelos de democracia social instaurados se desarrollan de acuerdo a perfiles muy característicos con variantes populistas, que responden a los patrones culturales de los países de la región, así pues, se puede observar esta realidad en cada uno de éstos. Ni 1 concepto ni el modelo de lo que significa la "democracia", es único, lineal o uniforme. Es un concepto-modelo que está atravesado por un ejercicio hermenéutico entre sentido y significado. Por lo que una democracia "desde arriba", es la democracia estatal; y una democracia "desde abajo" es la popular. Precisamente, ya la etimología de la palabra "democracia", implica una relación de correspondencia directa entre el pueblo y su autoridad o estado $($ demos $=$ pueblo y kratos $=$ autoridad o poder $)$, estableciéndose de esta manera como un sistema doctrinal que admite ampliamente la intervención del pueblo en las estructuras de poder, con el fin de su mejoramiento y la promoción de su bienestar (Martínez, 2011).

Uno de los teóricos representativos sobre la democracia, Montesquieu (16881755) la define como una de las formas de Estado en la que el poder está en manos del pueblo en su conjunto. De igual forma Bobbio (citado por Ferrajoli, s/f) la define como un conjunto de reglas (jurídicas), que aseguran los poderes de la mayoría, así como los límites impuestos a ésta para la garantía de valores tales como la libertad, igualdad y los derechos humanos. Estas concepciones nos proporcionan el marco analítico donde la variable de estudio educación democrática se desarrolla.

Como bien lo plantea Martínez (2011, p.18): "La democracia ha de aprenderse, no se tiene de nacimiento, y es la educación democrática la que nos permite compartir una forma de mirar el mundo". Con esto el autor contempla de forma directa la necesidad de establecer las circunstancias óptimas para que los ciudadanos sean capaces de convivir bajo diferentes escenarios visibles e intangibles, promoviendo una reflexión acera de la mayoría de las actividades cognitivas y morales, entre otras. Debe ser, sin lugar a dudas, una experiencia pública pues debe aprenderse por medio de las vivencias individuales y colectivas. 
Diálogos sobre educación democrática: mirada intercultural de la formación de ciudadanos latinoamericanos

Se puede aseverar, entonces, que ninguna sociedad es causada por fuerzas naturales; menos aún, las llamadas democracias a partir de la modernidad. El modelo de la democracia republicana a partir de la revolución francesa incorpora la actividad popular del pueblo en la construcción del Estado por medio de prácticas democráticas que sirvan de reconocimiento del otro en igualdad de condiciones.

Las sociedades no son democráticas por naturaleza, ya que los individuos van desarrollando actitudes, habilidades impregnadas de fundamentos axiológicos que les invitan a estructurar conductas cuyo sentido se cimiente en el bien consigo mismo y con el otro en una sociedad cada vez más global. Es la idea que sostiene Lledó (2009) que establece lo que para muchos significa un secreto a voces, al indicar que no puede haber educación ciudadana sin una auténtica democracia participativa.

El autor en cuestión ahonda en la concepción minimizada de democracia por muchos, que relega aspectos fundamentales del derecho a una educación democrática a meras prácticas parciales de la misma, tales como la libertad de expresión que restringe una acción directa por parte del ciudadano en la construcción de la opinión pública con lo que se aleja al ciudadano de una democracia del diálogo al nos apropiarse de facultades cognitivas que le permitan razonar las tipos de conflictividad social y sus posibles soluciones.

Según Apple y Beane (2005) el significado de democracia puede ser muy ambiguo dada su perspectiva de análisis. Es así como puede ser concebida como principio articulador de movimientos relacionados con derechos civiles, expansión del voto popular y libertad de expresión / pensamiento. También encuentra su acepción en la estructuración de mercados capitales cuyas políticas de acción son dominadas por sistemas de participación e inclusión económica.

No es el caso de profundizar en las concepciones filosóficas del Estado como "principio de orden regulatorio general, de unidad y de legalidad" (Torres, 2001, p.21), pues para los fines prácticos de la dirección relacional del objeto de estudio en cuestión, se trata de situar la interpretación de la democracia como un proceso que se 


\section{Nelson M. Manzaneroy Miguel Y. Ramírez.}

Telos Vol. 20, No. 1 (2018). 101-128

erige desde el pueblo, y no en forma inversa. El autor está consciente de la influencia del Estado en el establecimiento de las pautas democráticas que definen un sistema de educación ciudadana, sin embargo, busca fortalecer la esencia de lo hasta ahora expuesto, desde las bases democráticas comunes que se han instaurado en Latinoamérica donde la movilidad política para la obtención de mayores derechos políticos, implica una actuación manifiesta de los movimientos populares.

En aras de encontrar un escenario plenamente cuidado en el que confluyan los principios utópicos de la interculturalidad para consolidar un enfoque de educación que posteriormente se llamará democrática y que en el caso de ser necesario será tomado como referencia inequívoca, se parte de lo establecido por Hegel (Citado por Cayuela y Vara, 2012) quien define el Estado como una realidad capaz de alcanzar y perpetrar la libertad. Es allí donde confluyen lo particular y lo común y donde el individuo goza de una razón que pone al servicio del otro con el fin de afianzar el bienestar social. La libertad es preservada únicamente bajo la estructura de un Estado. Bajo este supuesto, los fundamentos de la interculturalidad cobran vida por sí mismos y se conforman como sustentos esenciales de la convivencia social en la búsqueda del bien común, el encuentro sensible que se mencionaba en los primeros apartados.

Seymour Martin Lipset (1987) hace referencia a una correlación auténtica entre educación, sociedad y democracia, al reconocer que los procesos inherentes a la formación del ser humano son condicionantes en el contexto donde se desenvuelven en ámbitos democráticos, determinan su existencia y progreso económico (por exigencia de espacio y extensión del reporte, no se especifican las escalas de democratización del autor y que sustentan tal correlación directa).

En un sentido más concreto y como producto de sus reflexiones Lipset demuestra que las prácticas democráticas vitales (elección, sufragio, participación ciudadana, entre otras) y la vivencia de valores en una sociedad, por encima de las diferencias que hacen únicos a los ciudadanos, son posibles únicamente a través del fortalecimiento de la educación. James Bryce (Citado por Lipset 1987, p.35) concluye 
Diálogos sobre educación democrática: mirada intercultural de la formación de ciudadanos latinoamericanos

diciendo: "La educación, si bien no hace de los hombres buenos ciudadanos, les facilita al menos que se conviertan en tales".

En este punto de nuestro discurso, se hace vital concretar fundamentos indisolubles de la educación por considerarse la única dirección infalible para la consolidación de una democracia que posteriormente se traduzca en una condición básica de avenencia con el otro, en términos de convivencia social. La educación es un proceso humano y cultural complicado. Para instituir su intención y su esclarecimiento es ineludible reflexionar la situación y naturaleza del individuo y de la cultura en su conjunto, en su totalidad, para lo cual cada característica tiene sentido por su vinculación e interdependencia con las demás y con el conjunto.

Ante tal premisa, la educación se concibe como un cúmulo de experiencias creativas cuyas simbolizaciones pueden ser consideradas altamente complejas, pues dependen no solo de las variables relacionadas con el contexto socio-cultural inmediato donde ocurre el hecho educativo, sino también de aquellas que diferencian un sujeto particular de otro. Y cómo estas diferencias se articulan para formar una personalidad que impulsa al individuo a actuar bajo ciertos comportamientos normados y consensados colectivamente. Ampliando lo anteriormente descrito, es en la educación en donde se forjan los sistemas de integración social y los patrones comportamentales de cada individuo. Es un espacio de socialización que propende a través de ella a la construcción política de un ser humano situado por contextos de acción que le permiten un reconocimiento de su autonomía personal, siempre y cuando se le ofrezca posibilidades para desarrollar habilidades de disciplina, de guiatura y de una consistente conducción (León, 2007).

La educación se centra en sujetos y no en objetos, con la firme convicción de profundizar en relaciones intersubjetivas que contribuyan permanentemente a una resignificación del pensamiento por medio de los lenguajes y los respectivos discursos, mediante los cuales la cultura logra sus valores universales en relación a sus modos de apropiación de conocimientos científicos y humanísticos, ético y estéticos, entre otros. 


\section{Nelson M. Manzaneroy Miguel Y. Ramírez.}

Telos Vol. 20, No. 1 (2018). 101-128

Educación y cultura se funden en la construcción de aquello que debe tener la característica de perdurable y que debe conformarse como patrones claros de la personalidad de los individuos que le ayudarán a su vez, en el desarrollo de habilidades de interrelación con su semejante (Gimeno y Pérez, 2000). En otras palabras, la educación y cultura se entrelazan para formar al ciudadano, el cual, posteriormente cumplirá funciones específicas al interior de la sociedad.

Surge, entonces, en un contexto próximo a la realidad latinoamericana, la necesidad de generar reflexiones sobre una educación democrática que, partiendo de las relaciones de confrontación y vinculación entre sus particularidades, puedan propiciar relaciones dialógicas a favor de prácticas interculturales que estimen como valiosa la ancestralidad y actualidad de quienes son interlocutores de su propia cultura.

A saber, la educación ciudadana juego un papel decisivo en la representación social del sentido común con el que los saberes de una cultura se formalizan para comprender el saber mítico y la episteme de su mundo de vida. Actualmente, por ejemplo, México se debate entre la necesidad de formar ciudadanos y la carencia de valores democráticos que promuevan actividad en los estudiantes de las aulas, e incentiven en ellos la vivencia de procesos de intervención social sanos, positivos adecuados al contexto, y que emerjan del propio currículo que rige la dinámica educativa del país (González Luna, 2010).

Educación ciudadana, educación cívica o bien educación para la democracia, son términos que han confluido en la realidad mexicana como sinónimos de una educación democrática, cuyo significado será analizado más adelante. Ramírez (2005) hace referencia a la educación ciudadana en México como una práctica incipiente, por la poca sistematización de experiencias y por el bajo nivel de concreción de las voluntades comunes. Los esfuerzos institucionales han quedado inconclusos por el casi nulo seguimiento organizacional que se les ha brindado a planificaciones relacionadas con la formación de ciudadanos capaces de convivir en sociedad. 
Diálogos sobre educación democrática: mirada intercultural de la formación de ciudadanos latinoamericanos

Contextualizando un tanto más el alcance del establecimiento de dichos procesos de formación ciudadana, el Instituto Nacional Electoral (2004) en su Programa Estratégico de Educación Cívica 2005 - 2010, señala lo siguiente:

\begin{abstract}
"La construcción e institucionalización de la ciudadanía ha sido un largo y accidentado proceso histórico, cuyo motor es el disenso social. [...] En las naciones en las cuales se produjo la innovación jurídica e institucional de los derechos de ciudadanía se presentó históricamente una correlación entre desacuerdos sociales, aprendizaje normativo e institucionalización jurídica. En otras palabras, la ley expresó no sólo un horizonte normativo deseable, sino un compromiso social exigible" (p.16).
\end{abstract}

Si bien es cierto que existen fundamentos sólidos legales que sustenten una posible vinculación de la educación con la democracia en México en su Carta Magna y Reglamentos particulares, existe también el desinterés latente y cada vez más creciente que promueva la formación de un ciudadano cada vez más empoderados hacia una construcción más positiva de su futuro: un individuo activo y plenamente comprometido con su realidad social por encima de inclinaciones egoístas o reducida a particulares. El camino es tortuoso y no puede inferirse que no se esté haciendo nada al respecto; sin embargo, con el afianzamiento de valores democráticos se puede consolidar un ciudadano capaz de autorealizarse como miembro activo de la sociedad y lo que es mejor, capaz de formar sentido de comunidad con el otro (Ramírez, 2005).

La educación democrática, entendida como procesos de formación e involucramiento activo social del individuo, equidista un tanto de las concepciones primitivas del término propuestas por Rousseau que implicaban la democratización de la enseñanza como un gobierno para todos, en donde los principios fundamentales giraban en torno a la consecución de una educación por y para el todo por medio de la vivencia de valores humanos universales (Sotelo, 1996). Las ideas filosóficas de Rousseau promovían en si la apertura de las organizaciones educativas como principio compensatorio de la desigualdad social de su contexto. 


\section{Nelson M. Manzaneroy Miguel Y. Ramírez.}

Telos Vol. 20, No. 1 (2018). 101-128

Si bien es cierto que no se puede alejar tal concepción histórica de la educación democrática moderna, el abordaje de la misma como variable de estudio en la presente investigación, implica la ejecución de determinados métodos y contenidos educativos/democráticos que formen al estudiante de manera activa en la convivencia ciudadana transcendiendo incluso de los tecnicismos propios de cada área del saber (Schmelkes, 2009).

En términos generales, la educación democrática debe conformarse como un eje transversal/longitudinal en el currículo educativo para la construcción efectiva de la democracia. La enseñanza como un referente del ejercicio de libertades personales no puede desligarse de la acción política, pues debe, al mismo tiempo, facilitar a los ciudadanos fundamentos consistentes de conocimientos en áreas socioeconómicas y desarrollar su capacidad de reflexión. Motivarles a participar de modo activo en la vida pública, social, sindical y cultural, ayudándoles a desarrollar su juicio crítico y analítico con la expresa finalidad de la legitimar el valor y sentido democratizador de sus decisiones y elecciones.

Por su parte, y en respuesta a los planteamientos expuestos anteriormente, Gutmann asevera que la educación democrática es una verdad compartida entre todos y cada uno de los actores del hecho educativo, entre los cuales señala: padres, directivos, maestros, oficiales públicos cuyos límites de participación y activación deben estar instituidos en los principios de la no discriminación y no represión (citado por Naval 2000).

El derecho más generalizable de una educación democrática radica en el respeto de las diferencias entre los que aprenden, sin perder de vista la quimérica noción de constituir un patrón de referencia común totalmente factible con lo diverso, puesto que la democracia en sí no es únicamente una gestión de gobierno de la mayoría, sino que al igual que la educación democrática, se conforma como una visión política de una sociedad, cuyos ciudadanos han sido formados e instruidos bajo un esquema educativo que los hace capaces de cohabitar con el otro y de participar tomando decisiones en forma conjunta. 
Diálogos sobre educación democrática: mirada intercultural de la formación de ciudadanos latinoamericanos

La democracia como la educación democrática se conforman como ideales políticos y educativos a la vez, pues el haber sido instruido o formado en diversas áreas del saber, implica haber sido gobernado en cierta forma, ya que no puede mandar alguien que no ha obedecido en alguna oportunidad (Dewey, 2004). Tanto la educación como la democracia fundamentan su quehacer en la promoción de una doble intencionalidad, ya que se conforman como los motores que potencializan las habilidades de los individuos y los hacen libres, garantizando su permanencia y subsistencia; y una segunda como un referente de vida al establecer patrones estructurales de organización, a través de los cuales la democracia es capaz de reinventarse plenamente gracias a la plataforma que le brindan las dinámicas educativas, siempre con el objetivo final de promover una convivencia social dada la confluencia y práctica de los valores universales.

Ahora bien, Naval (2000) establece un consistente diálogo sobre la educación democrática, en el que resalta que la educación como proceso de formación de ciudadanos no solamente establece la atmósfera para la interacción política de la sociedad, sino que también juega un papel focal en lo que ha sido una discusión por años sostenida en cuanto a la estructuración de una teoría democrática de la educación que invite a responder cuestionamientos como: ¿Quién debe compartir el poder para resolver cómo instruir ciudadanos libres y democráticos? y que Gutmann (Citado por Naval, 2000) posteriormente engloba en tres desafíos puntuales: ¿Por qué confiamos en una presunción para establecer lineamientos de quién debe ejecutar el poder sobre la educación? ¿Por qué una teoría democrática? y ¿Por qué dirigir nuestra mirada hacia la educación?

Ciertamente, estos cuestionamientos filosóficos llevarán a debatir las acciones propias entre lo moral y lo político en cada contexto por minúsculo que sea, pues de las actitudes y competencias de cada uno de los actores del hecho educativo depende la visión objetiva de aquello que es moralmente aceptado y políticamente justo o adecuado. Para ampliar un poco los retos que plantea Gutmann y desarrollar un tanto 


\section{Nelson M. Manzaneroy Miguel Y. Ramírez.}

Telos Vol. 20, No. 1 (2018). 101-128

una teoría de la educación democrática a fin de buscar una respuesta cónsona en el camino del saber, Naval (2000) despliega lo que, para él, se constituye como el centro de la misma y que define como modos de reproducción social.

Una teoría sobre la educación democrática se centra, entonces, en una reproducción social consciente e inconsciente de las prácticas y valores de una cultura en su flujo con respecto a la construcción de la ciudadanía y sus relaciones simbólicas y discursivas, con otras. Se trata de comprender "los modos en que los ciudadanos deben estar dotados de poder para influir en la educación, la cual a su vez forma los valores políticos, las actitudes y los modos de comportamiento de los futuros ciudadanos" (Naval, 2000, p.71). Partiendo de este supuesto se puede aseverar con toda claridad la relación de coexistencia que concurre entre la educación y la democracia, pues una teoría democrática contemplaría los quehaceres de capacitación intencionada y las afecciones pedagógicas de las organizaciones educativas en tres principios concretos: no represión, no discriminación y deliberación democrática.

Por otro lado, y continuando bajo la cosmovisión de Naval, muchas de las situaciones en las cuales tienen lugar el proceso educativo son meramente irreflexivas e involuntarias, por lo que también define una reproducción social inconsciente, lo que confirma tal premisa es que los estudios de socialización política tratan de encontrar respuestas concretas que expliquen el sentido de perpetuidad de las comunidades en sí mismas. Ante este escenario concluye aseverando que si el objetivo esencial de una supuesta teoría de la educación es dilucidar cómo los ciudadanos de una sociedad democrática deberían activarse para estructurar de manera consciente su futuro, conviene no relacionar la educación con las formas inconsciente de la política pues se trata de destacar la dirección cultural de la educación dentro de las prácticas racionales de la política 
Diálogos sobre educación democrática: mirada intercultural de la formación de ciudadanos latinoamericanos

\section{Conclusiones}

La educación democrática surge como simbiosis ineludible entre los parámetros culturales de una sociedad y el poder que la rige, dejando entrever los niveles de concreción bajo los cuales debe consolidarse como proceso continuo y permanente. En su presupuesto más básico, la educación está comprometida conla formación de ciudadanos a partir de procesos interculturales que se fundamentan en los principios propios de la democracia: libertad, igualdad, pluralismo y participación. En la búsqueda incesante por promover un realismo tangible a lo que para muchos sería una utopía, Apple y Beane (2005), plantean ciertas condiciones que deben cumplirse para el establecimiento de fundamentos democráticos, con cimiento tangibles de diálogos entre culturas en los centros de educación formal. Estos son:

- Una apertura hacia la libre expresión de ideas, que en términos cabales se constituya el principio justificativo de una sociedad plural. Se trata de gestar un significado de libertad, más allá de la mera palabra, que implique cualquier posibilidad de expresión y pensamiento. Alarcón (2012) expresa que la libertad democrática impulsa la confianza de los ciudadanos en sí mismos; en otras palabras, alienta el ejercicio mismo de la libertad. "Los principios de confianza y empatía social deben estar presentes dentro de los individuos, quienes deben ser conscientes de su responsabilidad para adoptar permanentemente actitudes respetuosas ante las opiniones y acciones de los demás" (p. 59).

- El desarrollo de la fe en el individuo y en la capacidad colectiva en la resolución de conflictos. John Dewey (2004) hace referencia al sentido de la eficacia social como el eje integrador que mueve los parámetros circundantes de la relación democracia y educación, haciendo referencia a la socialización del espíritu que impulsa a todo ser humano a trabajar y a comunicarse con el otro, y al necesario rompimiento de las barreras de estratificación social que hacen impenetrables la humanidad de los ciudadanos y que irrumpen en la confianza que se pueda o no generar entre ellos. Es así como cobran vida los 


\section{Nelson M. Manzaneroy Miguel Y. Ramírez.}

Telos Vol. 20, No. 1 (2018). 101-128

enfoques sistémicos en la educación democrática que se construye en una sociedad intercultural, en donde el todo no solo lo conforma la suma de sus partes, sino la interrelación de sus componentes con las condiciones y realidades de cada individuo.

- $\quad$ El arraigo de una reflexión intercultural, en donde se promueva el uso de la cavilación crítica y procesos de análisis en la evaluación de ideas, problemas y políticas. Naval (2000) hace referencia a la necesidad del diálogo reflexivo en el ciudadano, que trascienda de la mera reflexión teórica, para abordar problemas prácticos, entrelazados con premisas reales de comunidades también reales. Es necesario que la educación democrática, a través de una pedagogía intercultural, prepare al individuo no únicamente para negociar ciertas posturas, sino, por el contrario, dialogar con sus semejantes y construir acciones que promuevan una mejora tangible a eso que conocemos como sociedad.

- La necesidad del otro en la promoción del bien común. La concepción de cultura y del reconocimiento - respeto - encuentro de culturas debe estar arraigada en los procesos de la educación democrática, como fundamento sólido e inamovible de la misma, pues es en la construcción conjunta en donde se consolidarán acciones que promoverán beneficios mutuos globales y no para particulares. Para Apple y Beane (2005) el bien común es el pilar esencial de las escuelas democráticas, siempre y cuando se promueva la exaltación cuidada del pensamiento individual como referente válido y puntual en la construcción del pensamiento colectivo. Los principios de todos cuentan, es imprescindible, ya que un ser humano solitario y una población cerrada son abstracciones fuera de contexto.

- $\quad$ El entendimiento correcto de la democracia como un sistema de valores que se debe vivir y que rige el comportamiento de ciudadanos, en donde los estudiantes sean capaces de internalizar el verdadero sentido del ser 
Diálogos sobre educación democrática: mirada intercultural de la formación de ciudadanos latinoamericanos

democrático, más allá del mero adoctrinamiento político, con una amplia provisión de herramientas críticas que le inviten a trascender y a establecer juicios entre aquello que es verdadero y falso, aquello irreal y real, aquello superfluo o profundo (Magendizo, 2004).

- La organización de instituciones sociales para promover y extender los principios democráticos. El estudiante, bajo un esquema de educación democrática, debe ser involucrado de forma directa o indirecta con el otro, partiendo de motivaciones comunes que les impulsen a extender los principios democráticos de convivencia, libertad, bien común y por sobre todas las cosas de solidaridad. Tal y como lo expresa Naval (2000) el fortalecimiento de una teoría de educación democrática dependerá en gran manera de la consolidación de un individuo que se presente y actúe bajo parámetros de ayuda comunitaria, de servicio al otro. Por ello la mejor vía de perpetuar la concepción democrática en el llamado ciudadano, es a través de la promoción de organizaciones netamente sociales de ayuda mutua y de asistencia copartícipe.

Lo anteriormente descrito se conforma como una concisa estructuración del sustento teórico de la construcción de la educación democrática en escenarios interculturales, aseverando que tales construcciones podrán ser efectivamente tangibles en la medida que se establezcan andamios sólidos, impregnados de procedimientos y normativas que vislumbren la vivencia democrática institucional; así como el fortalecimiento de prácticas democráticas con el otro en los diseños curriculares que se consoliden.

El ser social de la vida ciudadana va a depender de la formación democrática de sus principales actores, vale decir, del mismo pueblo o colectivo humano organizado por medio de las instituciones de la política y la centralidad del Estado. La tarea a realizar es logran principios, normas y prácticas dialógicas que hagan viable la comunicación y la opinión pública crítica entre quienes participan, desde las diferencias en situaciones de contexto, con el propósito de relativizar las asimetrías y 
Nelson M. Manzaneroy Miguel Y. Ramírez

Telos Vol. 20, No. 1 (2018). 101-128

propiciar analogías o semejantes que atiendan la igualdad, la equidad y sentido de participar en la política a través de instancias democráticas y de derechos humanos.

\section{Referencias bibliográficas}

Alarcón, Victor (2012).Libertad y Democracia. Cuadernos de divulgación de la cultura democrática. Instituto Nacional Electoral Ediciones. México.

Apple, Michael y Beane, James (2005).Escuelas democráticas. Ediciones Morata. España.

Bolívar, Antonio (2016) Educar Democráticamente para una Ciudadanía Activa.Revista Internacional de Educación para la Justicia Social (RIEJS), Volumen 1， N5.(Pp.69 - 87). España. Extraído de: https://revistas.uam.es/riejs/article/viewFile/4344/4717 consulta: 06/07/17.

Cayuela, Aquilino y Vara, Julián (2012).El curso de la Historia.Erasmus Ediciones. España.

Della Ventura, Aitor (2016).Género, Identidad y Performatividad en Judith

Butler.Tesis Doctoral. Doctorado en Filosofía. Universidad de la Laguna. España.

De Vallescar, Diana. (2013) Interculturalidad, espacios interculturales y la referencia ético - moral. Utopía y Praxis Latinoamericana.Volumen 18,Número 60, (Pp. $69 \quad-\quad 79) . \quad$ Venezuela. Extraído de: http://www.redalyc.org/pdf/279/27926711014.pdf consulta: 25/06/17.

Dewey, John. (2004).Democracia y Educación.Ediciones Morata. España.

Ferrajoli, Luigi. (s/f).Norberto Bobbio. Teórico del Derecho y la Democracia. Universidad Autónoma de México. México.

Fornet Betancourt, Raúl. (2000) Interculturalidad y Globalización. Editorial DEI. Costa Rica.

Fornet Betancourt, Raúl. (2009). Tareas y Propuestas de la Filosofía Latinoamericana. VerlagMainz. Alemania.

Fraufe Quintas, Sindo. (2015).Hacia una Pedagogía de la Interculturalidad.Universidad de Salamanca. España.

García Canclini,Néstor. (2006). Diferentes, desiguales y desconectados. Mapas de laInterculturalidad. Editorial Gedisa. España.

Gimeno, José y Pérez, Ángel (2000).Comprender y transformar la enseñanza. Ediciones Morata. España. 
Diálogos sobre educación democrática: mirada intercultural de la formación de ciudadanos latinoamericanos

González Luna, Teresa (2010).Democracia y Formación Ciudadana. Instituto Federal Electoral. México.

Instituto Nacional Electoral (2004).Programa Estratégico de Educación Cívica 2005 - 2010) Instituto Nacional Electoral Ediciones. México

León, Aníbal. (2007).¿Qué es la Educación?Universidad de los Andes. Venezuela.

Lipset, Seymour (1987).El hombre político.EditorialTécnos. España.

Lledó, Emilio (2009).Ser quien eres. Ensayos para una educación democrática.

Prensas Universitarias. España.

Magendizo, Abraham (2004).De miradas y mensajes en la educación de derechos humanos. Editorial LOM. Chile.

Manzanero-Márquez, Diana. (2014) Encuentro de Subjetividades en torno al género: Acercamiento al pensamiento feminista desde la interculturalidad. Tesis de maestría. Especialidad de Filosofía Universidad Católica Cecilio Acosta. Venezuela

Martínez, Juan. (2011) La educación democrática en los nuevos escenarios ciudadanos. Revista Interuniversitaria de Formación del Profesorado (RIFOP).Número 71 (25.2), (Pp. 17 - 44). España.Extraído de: http://aufop.blogspot.mx/2011/07/la-educacion-democratica-en-losnuevos.html consulta 15/06/15.

Naval, Concepción (2000).Educar ciudadanos, la polémica liberal-comunitarista en educación. Ediciones Universidad de Navarra. España.

Ramírez, Gloria (2005).La Educación Ciudadana ante los retos de la democracia en México. UNESCO. México.

Salas Astrain, Ricardo (2003). Ética intercultural. Ediciones UCSH. Chile.

Schmelkes, Silvia (2009).Interculturalidad, democracia y formación valoral en México.Revista electrónica de investigación educativa, Volumen 11, Número 2,(Pp. 1 - 10). México. Extraído de: https://redie.uabc.mx/redie/article/view/233/391 consulta: 05/07/14.

Sotelo, Ignacio (1996) Educación democrática. Estudios. filosofía-historia-letras (Verano-Otoño), Biblioteca Itam.Extraído de: https://biblioteca.itam.mx/estudios/estudio/letras45-46/texto02/sec 1.html Consulta: 05/07/14.

Torres, Carlos (2001).Democracia, Educación y Multiculturalismo. Editorial Siglo XXI. España. 